\title{
FUNGSI MUSIK NDOTO DALAM RITUAL NGAGHA MERE
}

\author{
Blandina Wenika Djawa \\ Jurusan Etnomusikologi Institut Seni Indonesia Yogyakarta
}

\begin{abstract}
Abstrak
Ndoto merupakan salah satu instrumen musik yang cukup penting dalam ritual Ngagha Mere, sebuah ritual mengucap syukur dan memberikan ubi jalar sebagai persembahan kepada leluhur yakni ine ame ebu kaju, oleh masyarakat Wajo di Kabupaten Nagekeo, Flores, Nusa Tenggara Timur. Pentingnya fungsi Ndoto dalam ritual maka masyarakat adat pun tidak memperbolehkan memainkan setelah upacara selesai bahkan ndoto harus dibelah dan dibakar untuk menjadi sumber api bagi ubi Jalar. Fakta ini menjadi sebuah fenomena yang menarik untuk ditelaah.

Fenomena dijadikannya ndoto yang tidak boleh dimainkan dan menjadi sumber api dalam prosesi ritual Ngagha Mere dalam konteks kebudayaan adalah sebuah kasus permasalahan sehingga jenis penelitian ini menggunakan kualitatif studi kasus dengan teknik pengumpulan data berupa observasi dan wawancara.

Hasil menujukkan bahwa fungsi ndoto dalam ritual Ngagha Mere adalah sebagai sarana komunikasi.
\end{abstract}

Kata Kunci: Fungsi, Musik Ndoto, Ngagha Mere,

\begin{abstract}
Ndoto is one of the musical instruments that is quite important in the Ngagha Mere ritual, a ritual of giving thanks and giving sweet potato as an offering to the ancestors, namely ine ebu kaju, by the Wajo people in Nagekeo District, Flores, East Nusa Tenggara. The importance of Ndoto's function in rituals also did not allow the indigenous people to play after the ceremony was completed and even the photos had to be split and burned to become a source of fire for Sweet Potatoes. This fact becomes an interesting phenomenon to be explored.

The phenomenon of making photographs that should not be played and become a source of fire in the ritual procession of Ngagha Mere in the context of culture is a case of problems so that this type of research uses qualitative case studies with data collection techniques in the form of observation and interviews.

The results show that the function ndoto in the Ngagha Mere ritual is a means of communication.
\end{abstract}

Keywords: Ngagha Mere, Ndoto's music. 


\section{Pendahuluan}

Ritual Ngagha Mere adalah ritual mengucap syukur dan memberi persembahan kepada para leluhur sebagai bentuk rasa terima kasih masyarakat Wajo atas perlindungan, keberhasilan kerja yang telah diberikan kepada mereka, dan yang menjadi persembahan adalah Uwi (ubi jalar liar). Ritual Ngagha Mere biasa dilaksanakan pada bulan Juli di setiap tahunnya. Pada tahun 2018, ritual tersebut dilaksanakan pada tanggal 7 Juli sampai 16 Juli. Ritual Ngagha Mere terdiri dari beberapa tahap, yakni Wuku (memanggil), La'e Mbue (membelah daun kacang), Mendi Mbue Kaju Api Ida (membawa kacang hijau), Ka Ngagha (makan kacang hijau), Lemba Uwi (cari ubi), Bhei Uwi (pikul ubi), Ka Uwi (makan ubi) yang dilaksanakan selama tiga malam berturutturut, dan Rio atau mandi (wawancara,Jogo :2018).

Bagian atau tahap yang paling penting dalam ritual tersebut adalah Bhei Uwi (pikul ubi), karena pada tahap ini ubi akan dipersembahkan kepada para leluhur. Ritual Ngagha Mere tidak terlepas dari musik yang memiliki peran penting dalam pelaksanaannya, yakni musik Ndoto.
Musik Ndoto merupakan musik yang penting dimainkan dalam ritual, yakni pada malam sebelum pelaksanaan Bhei Uwi (pikul ubi), serta pada pelaksanaan Bhei Uwi. Alat musik terebut terbuat dari bambu betung yang sudah tua dan dipotong dengan ukuran satu ruas, kemudian dilubangi di bagian tengahnya. Alat musik Ndoto dimainkan dengan cara dipukul dengan menggunakan kayu. Jumlah alat musik Ndoto yang dimainkan adalah 16 buah, dan masing-masing pemain memainkan dua alat musik Ndoto. Selain alat musik Ndoto, ada pula sebuah gendang yang dimainkan bersamaan dengan alat musik tersebut. Gendang tersebut terbuat dari kayu Ndora (kayu yang berongga), dan membran atau selaputnya terbuat dari kulit sapi.

Musik Ndoto memiliki beberapa ragam, dan ragam yang dimainkan dalam ritual Ngagha Mere yang dilaksanakan pada tahun 2018 adalah ragam gore ine oe, ma'e taku goe (jangan takut dengan segala beban, melainkan harus tetap dijalani) dan ragam ndua reta uma nuka wodo ko'u, bhida kodo ta tekuku tekuku (dalam menyelesaikan suatu pekerjaan walapun berat, tetap harus dijalani agar memperoleh hasil yang memuaskan meski lelah). 
Ragam-ragan tersebut mencerminkan kehidupan masyarakat Wajo, yang kemudian diaplikasikan ke dalam musik.

Keunikan dari alat musik Ndoto adalah setelah dimainkan dalam ritual, alat musik ini akan dibanting sehingga terbelah menjadi beberapa bagian, kemudian dijadikan kayu bakar guna merebus ubi (ubi yang telah dipersembahkan kepada para leluhur). Yang dijadikan kayu bakar untuk merebus ubi hanya alat musik Ndoto, sedangkan gendang akan disimpan kembali di rumah adat untuk kemudian dimainkan lagi dalam ritual Ngagha Mere pada tahun-tahun berikutnya.

\section{Fungsi Musik Alan P. Meriam, elaborasi dengan Merton}

Menurut Meriam (1976: 219-226) bahwa fungsi musik antara lain: (1) Sebagai sarana pengungkapan emosi, (2) kepuasan estetis, (3) seni hiburan, (4) sarana komunikasi, (5) persembahan simbolis, (6) Respon fisik, (7) pengukuhan institusi social dan upacara keagamaan, (8) kelangsungan dan stabilitas budaya, (9) pengukuhan norma masyarakat, (10) integritas masyarakat. Meriam juga menambahkan bahwa nilai guna dan fungsi musik merupakan faktor penting dalam etnomusikologi terutama mempelajari perilaku seseorang. Saat kita membicarakan nilai guna musik, kita akan berbicara mengenai peran musik dalam kehidupan sosial kemasyarakatan, lingkungan ataupun yang berhubungan dengan aktifitas.

Elaborasi Meriam mengenai fungsi music dalam konteks kebudayaan atau berhubungan dengan aktifitas masyarakat mempunyai persamaan dengan upaya Merton (dalam Kaplan dan Maners: 2011) bahwa fungsi dalam konteks kebudayaan dapat bertukar posisi yaitu dengan fungsi manifest dan fungsi latens. Fungsi manifest adalah konsekuensi obyektif yang memberikan sumbangan pada penyesuaian atau adaptasi system yang dikehendaki dan disadari oleh partisipan tersebut sedangkan fungsi latens adalah konsekuensi obyektif dari suatu ihwal budaya yang tidak dikehendaki atau disadari oleh warga, tetapi karena kebutuhan posisi fungsi tersebut dapat menjadi oposisi biner atau terbalik.

\section{Habitus, Modal dan Arena}

Legimitasi kekuasaan dipandang dari teori masyarakat tidak lepas dari 3 
aspek penting yang dijelaskan oleh Bordieu (1993) yaitu habitus, modal dan arena. Habitus adalah kebiasaan masyarakat yang melekat pada diri seseorang dalam bentuk disposisi abadi, atau kapasitas terlatih dan kecenderungan terstruktur untuk berpikir, merasa dan bertindak dengan cara determinan, yang kemudian membimbing mereka

Modal adalah unsur yang memungkinkan kita untuk mendapatkan kesempatan-kesempatan di dalam hidup. Modal bisa diperoleh, jika orang memiliki habitus yang tepat dalam hidupnya Dimensi modal disini beragam, seperti modal sosial, modal budaya, maupun modal ekonomi.

Modal memainkan peran yang cukup sentral dalam hubungan kekuatan sosial. Dimana modal menyediakan sarana dalam bentuk non-ekonomi dominasi dan hierarkis, sebagai kelas yang membedakan dirinya. Modal merupakan simbolik dari adanya ketimpangan dalam masyarakat. Dimana masyarakat terstratifikasi dari kepemilikan modal.

Arena merupakan wadah bagi habitus dan modal untuk memberikan nilai eksistensi terhadap seseorang atau kelompok sosial

\section{Metode Penelitian}

Penelitian ini menggunakan kualitatif studi kasus, yaitu sebuah penelitian kualitatif yang menekankan pada sebuah permasalahan yang terjadi dalam sebuah komunitas atau kelompok sosial kemasyarakatan.

\section{Hasil dan Pembahasan}

\section{Bentuk Penyajian Musik Ndoto dalam Ritual Ngagha Mere}

Bentuk dalam pengertian yang paling abstrak berarti struktur, artikulasi, arti menyeluruh dari hubungan berbagai faktor yang saling bersangkutan, atau lebih tepatnya cara dirakitnya keseluruhan aspek (Langer, 2016: 18). Penyajian dapat diartikan sebagai sesuatu yang siap untuk disajikan, cara menyajikan, mengatur atau menata sesuatu dan lain sebagainya. Bentuk penyajian musik Ndoto dalam ritual Ngagha Mere merupakan suatu hal yang terstruktur dan saling bersangkutan antara satu dengan yang lain, dengan memperhatikan beberapa aspek non 
musikal dan aspek musikal. Aspek non musikal mencakup tempat penyajian, waktu penyajian, pelaku pertunjukan dan lain sebagainya. Musik Ndoto dimainkan di rumah adat pada malam sebelum ubi dipikul, sebagai pertanda bahwa ubi telah sah untuk dipersembahkan kepada para leluhur, dan yang memainkan musik tersebut adalah anak-anak yang berusia sekitar 7-15 tahun. Musik Ndoto juga dimainkan pada tahap Bhei Uwi (pikul ubi) dengan ketentuan-ketentuan sebagai berikut. (1) pemain musik adalah pria dewasa guna mengantisipasi adanya kesalahan dalam memainkan musik; (2) para pemain harus mengenakan sarung adat; (3) tidak boleh ada kesalahan dalam memainkan musik Ndoto. Para pemain musik Ndoto memainkan musik dengan posisi menghadap ke Peo (simbol persatuan dan persaudaraan masyarakat Nagekeo). Secara aspek musikal, ada dua instrumen yang dimainkan dalam tahap Bhei Uwi, yakni Ndoto dan gendang. Ndoto merupakan alat musik yang termasuk dalam kelompok Idiophone, yakni sumber bunyinya berasal dari benda padat seperti logam, dan lain sebagainya, dan gendang termasuk dalam kelompok membranophone, yakni sumber bunyinya berasa dari selaput yang dibentang (Hendarto, 2011:4).

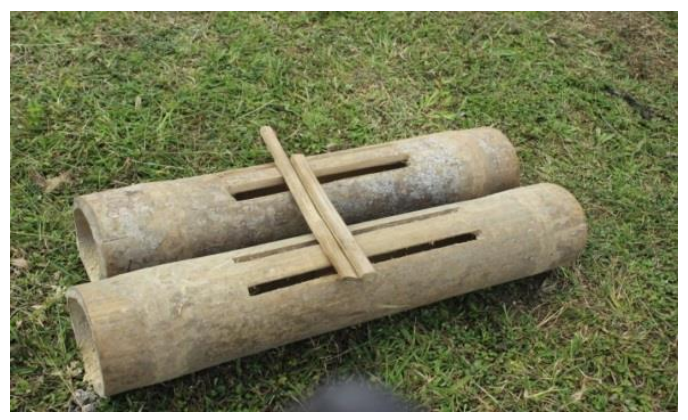

Gambar 1. Alat musik Ndoto

(Foto: Blandina Wenika Djawa, 13 Juli 2018)

\section{Pola Permainan Musik Ndoto dalam Ritual Ngagha Mere}

Musik Ndoto memiliki beberapa ragam atau pola permainan, yakni ragam gore ine oe, ma'e taku goe (jangan takut dengan segala beban melainkan harus bisa dijlani), ragam ndua reta uma nuka wodo ko'u, bhida kodo ta tekuku tekuku (dalam melakukan suatu pekerjaan walaupun berat, tetap harus dijalani agar memperoleh hasil yang memuaskan meski lelah), dan ragam ana kolo dasi lau bata bai (memohon kepada Tuhan dan leluhur, agar segala pekerjaan dapat memperoleh hasil yang memuaskan). Ragam-ragam yang dimainkan tergantung dari tabuhan gendang. Gendang akan terlebih dahulu dimainkan, dan ketika gendang dimainkan, 
para pemain musik Ndoto akan mengetahui ragam apa yang dimainkan. Dan yang dimainkan pada tahap Bhei Uwi dalam ritual Ngagha Mere yang dilaksanakan pada tahun 2018 adalah ragam gore ine oe, ma'e taku goe (jangan takut dengan segala beban, melainkan harus bisa dijalani) dan ragam ndua reta uma nuka wodo ko'u, bhida kodo ta tekuku tekuku (dalam melakukan suatu pekerjaan walaupun berat, tetap harus dijalani agar memperoleh hasil yang memuaskan meski lelah). Pola permainan kedua ragam tersebut adalah sebagai berikut.

1. Ragam gore ine oe, ma'e taku goe a. Motif gendang (solo)

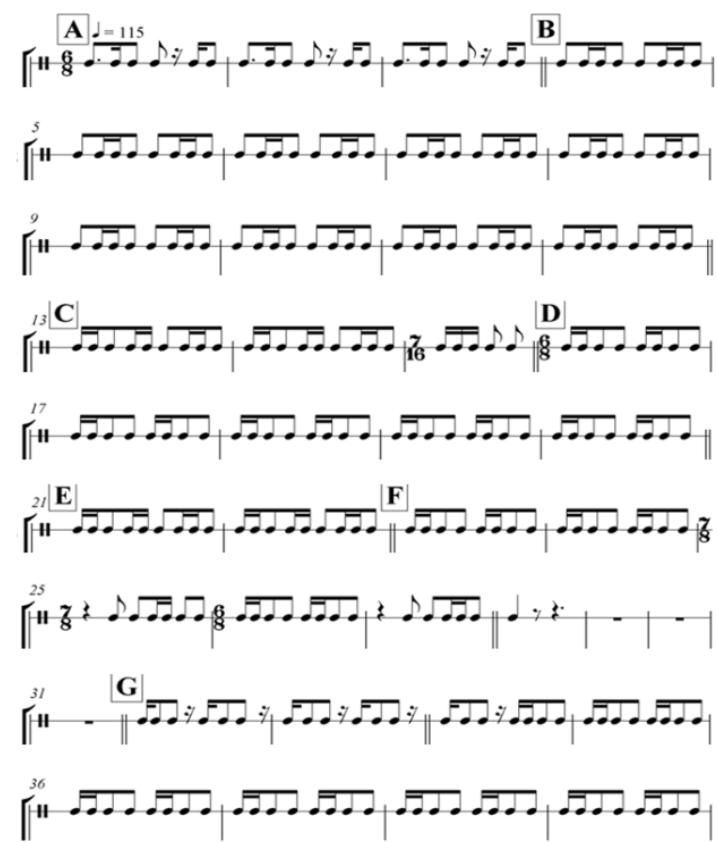

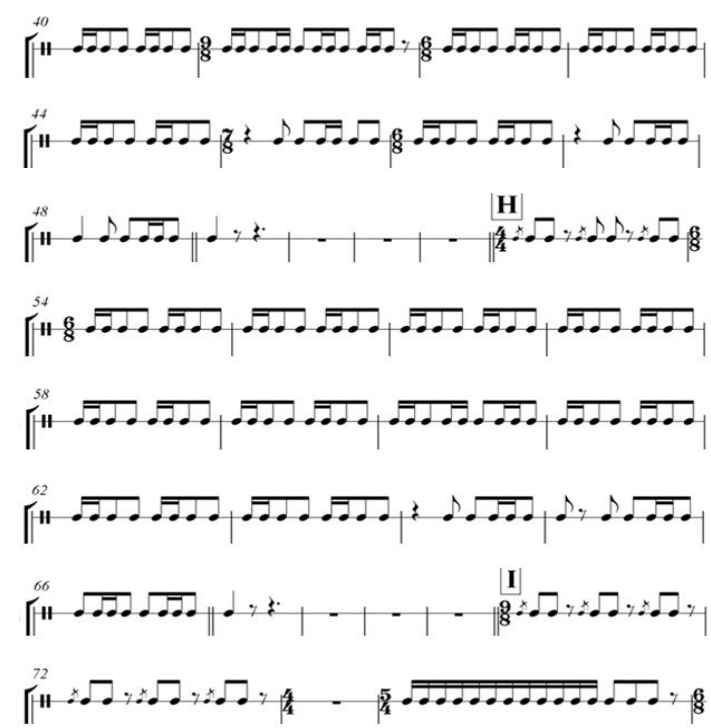

b. Motif Ndoto 1 (unison)

Motif-motif yang dimainkan dalam ragam gore ine oe, ma'e taku goe (jangan takut dengan segala beban, melainkan harus bisa dijalani) dimainkan dengan tempo cepat dan penuh semangat, melambangkan semangat masyarakat Wajo dalam menjalankan kehidupan meskipun ada beban dalam hidup.

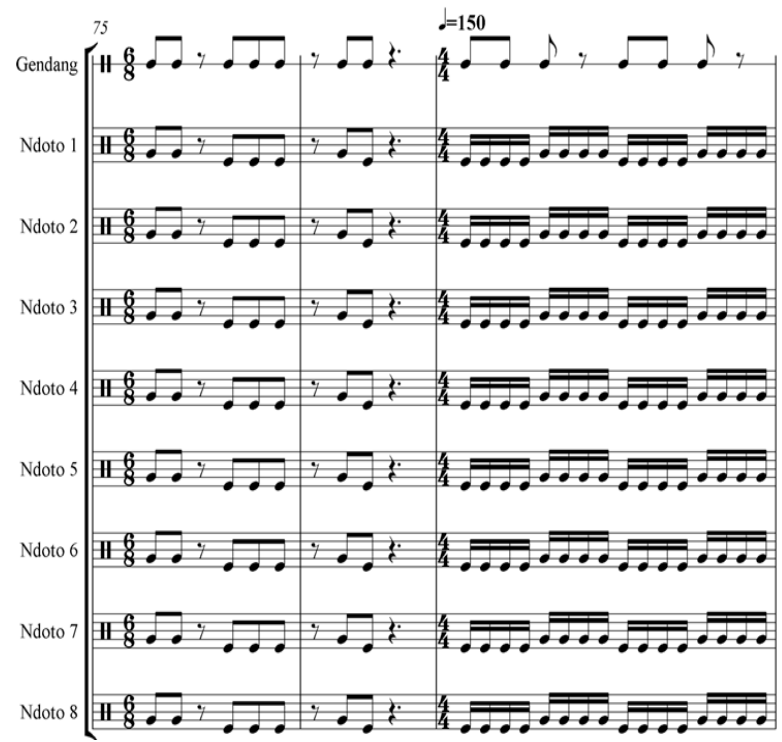


2. Motif Ndua reta uma nuka wodo ko'u, bhida kodo ta tekuku tekuku
a. Motif Ndoto 1
b. Motif Ndoto 2
c. Motif ndoto 3
d. Motif ndoto 4

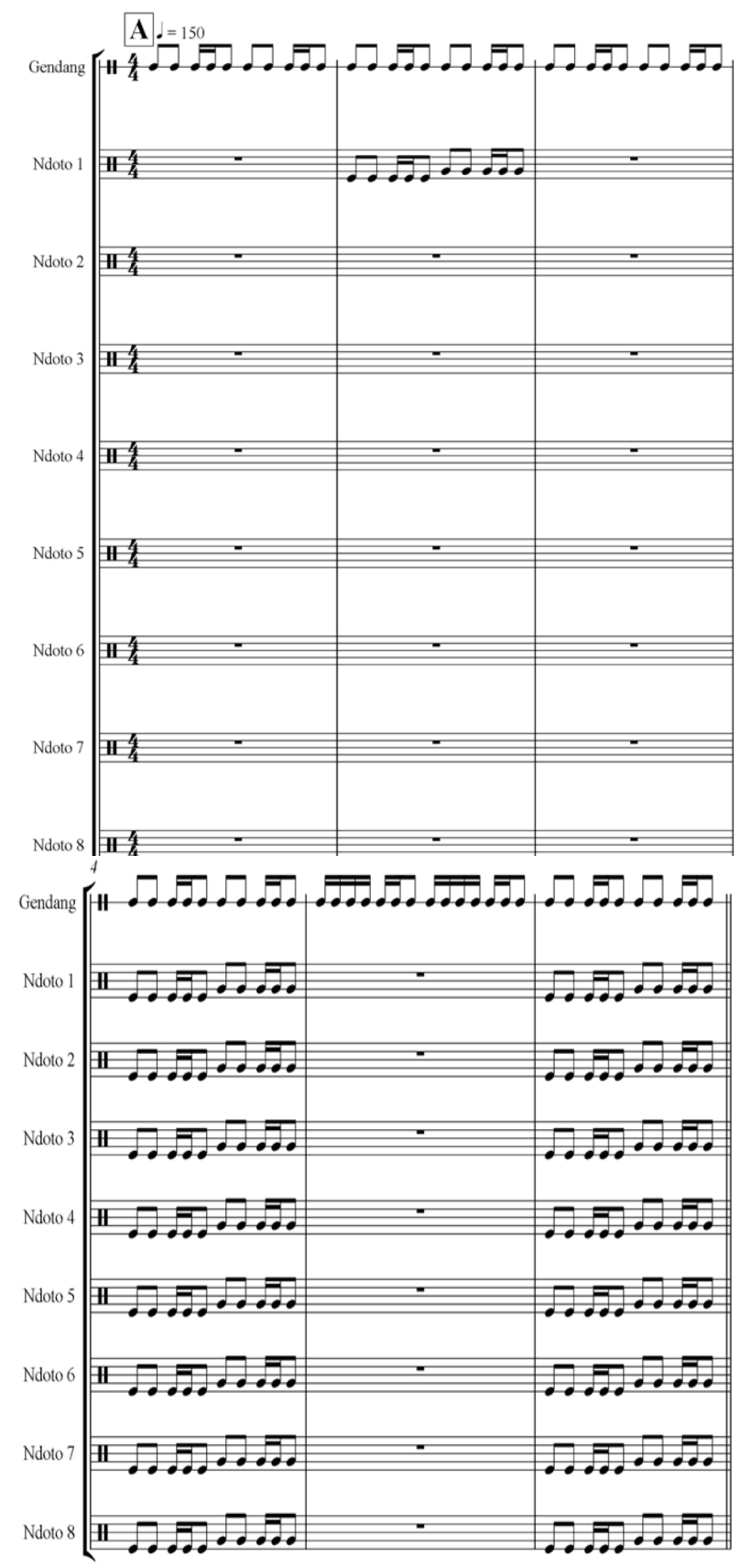

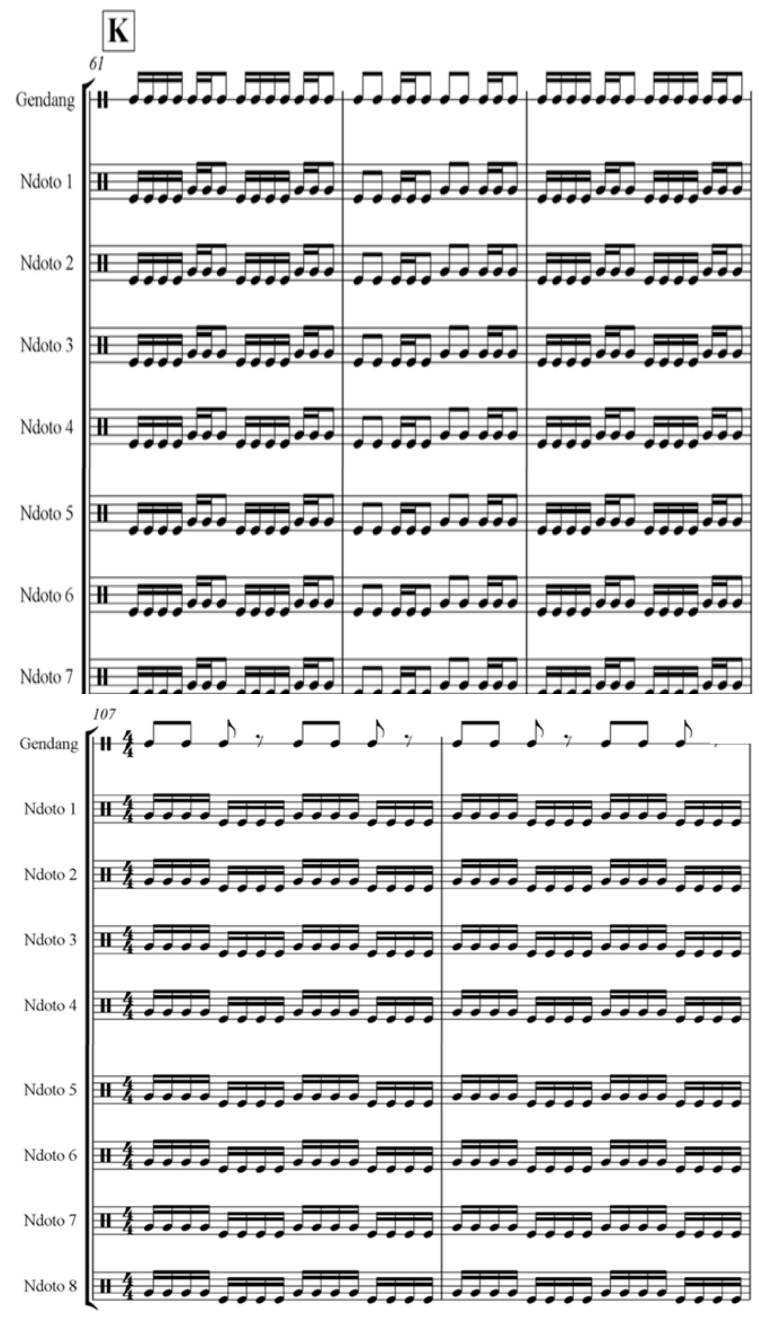

Ragam ini dimainkan dengan cara bersahut-sahutan antara para pemain musiknya (pada motif 1), kemudian para pemain akan memainkan musik Ndoto secara bersama-sama. Ragam ini juga berkaitan erat dengan kehidupan masyarakat Wajo, yakni dalam melakukan suatu pekerjaan meskipun sulit, tetap harus dijalani agar hasilnya memuaskan meski lelah. Motif pukulan dengan gaya 
bersahut-sahutan tersebut melambangkan ada salah satu masyarakat yang sedang mengalami kesulitan, namun tidak perlu khawatir karena masyarakat yang lain ada untuk membantu. Dengan kata lain, ragam ini diartikan sebagai kehidupan gotongroyong masyarakat Wajo yang telah ditanamkan sejak jaman leluhur. Salah satu contoh gotong-royong dalam kehidupan masyarakat Wajo adalah ketika salah satu masyarakatnya ada yang melakukan hajatan, maka bukan hanya masyarakat itulah yang mempersiapkan segala keperluan untuk hajatan, melainkan masyarakat yang lain juga ikut membantu. Serta masyarakat yang masih memiliki hubungan kekerabatan dengan pemilik hajatan juga ikut membantu baik dari segi materi dan lain-lain. Hal tersebutlah yang kemudian diaplikasikan dalam ragam permainan musik Ndoto.

\section{Fungi Musik Ndoto dalam Ritual}

\section{Ngagha Mere}

Secara garis besar, seni pertunjukan memiliki tiga fungsi primer, yaitu (1) sebagai sarana ritual; (2) sebagai hiburan pribadi; (3) sebagai presentasi estetis. Musik Ndoto adalah sebuah pertunjukan musik yang ditampilkan sebagai sarana ritual, dan oleh masyarakatnya dianggap sangat penting. Pada pertunjukan untuk kepentingan ritual ini, penikmatnya adalah para penguasa dunia atas dan bawah, sedangkan manusia sendiri lebih mementingkan tujuan dari upacara itu, dibandingkan menikmati bentuknya. Hal serupa terjadi pada masyarakat Wajo dalam ritual Ngagha Mere, yakni permainan musik Ndoto bukan sebagai hiburan bagi masyarakatnya, melainkan sebagai sarana komunikasi kepada para leluhur mereka yakni ine ame ebu kaju. Masyarakat Wajo percaya bahwa ketika musik Ndoto dimainkan, maka para leluhur mereka akan mendengarkannya, dan ketika para leluhur mendengar musik tersebut, leluhur akan mengetahui bahwa anak cucunya datang untuk memberikan persembahan. Selain itu, musik Ndoto juga dimainkan sebagai tanda bahwa uwi (ubi) telah resmi untuk direbus. Oleh sebab itu, musik Ndoto tidak dimainkan lagi di kampung adat Wajo ketika sedang tidak ada ritual Ngagha Mere. 


\section{Penggunaan Alat Musik Ndoto}

\section{Sebagai Kayu Bakar}

Alat musik Ndoto selain dimainkan sebagai sarana komunikasi kepada para leluhur, juga memiliki kegunaan lain dalam ritual Ngagha Mere. Alat musik Ndoto akan dibanting sehingga terbelah menjadi beberapa bagian, dan dijadikan kayu bakar untuk merebus ubi. Proses membelah alat musik Ndoto berlangsung pada malam setelah ubi dipersembahkan kepada para leluhur, lebih tepatnya pada tahap $K a U w i$ (makan ubi). Ka Uwi atau maka ubi (selama tiga malam berturutturut) dilaksanakan dengan alat musik Ndoto sebagai kayu bakar untuk merebus ubi. Dalam pelaksanaannya, salah satu masyarakat akan mengeluarkan alat musik Ndoto dari rumah adat, dan mulai membelah alat musik terebut menjadi beberapa bagian (dengan cara dibanting), dan proses membelah alat musik tersebut berlangsung di depan rumah adat.

Msyarakat Wajo memiliki prinsip bahwa alat musik Ndoto yang telah dimainkan dalam ritual adalah alat musik yang hanya diperuntukkan bagi para leluhur, sehinggat tidak boleh dimainkan di luar kampung adat dan dipakai atau dimainkan lagi adalam acara atau kegiatan lain. Sehingga untuk mengantisipasi adanya permainan alat musik Ndoto (Ndoto yang telah dimainkan saat ritual), alat musik tersebut dimanfaatkan sebagai kayu bakar untuk merebus ubi. Tetapi jika dihubungkan dengan kehidupan masyarakat Wajo, maka dapat diinterpretasikan pembuatan lat musik Ndoto, permainan alat musik Ndoto, dan penggunaan alat musik Ndoto sebagai kayu bakar merupakan gambaran dari kehidupan masyarakat Wajo sendiri, yakni mereka dilahirkan (pembuatan alat musik Ndoto), menjalani kehidupan (permainan alat musik Ndoto), dan sampai pada kematian (penggunaan alat musik Ndoto sebagai kayu bakar.

Masyarakat Wajo selain membuat alat musik Ndoto untuk kepentingan ritual, juga membuat alat musik ini untuk hiburan dan untuk sarana latihan bagi mereka sendiri, terutama bagi anak-anak sebagai generasi penerus Wajo. Namun, alat musik yang dibuat untuk hiburan dan latihan tidak dibawa ke kampung adat, melainkan disimpan di luar kampung adat (di salah satu rumah warga). Alat musik Ndoto tersebut yang kemudian akan dipakai untuk melatih anak-anak dan muda-mudi desa Wajo, agar tetap ada penerus untuk 
memainkan alat musik ini. Alat musik yang digunakan sebagai sarana latihan tidak dibakar, melainka disimpan agar bisa kembali dipakai.

Musik Ndoto adalah musik yang sakral bagi masyarakat Wajo, karena musik tersebut sangat penting peranannya dalam arena berupa ritual Ngagha Mere, khususnya pada tahap Bhei Uwi (pikul ubi). Pemain alat musik Ndoto terdiri dari 8 orang san 1 orang pemain gendang. Dalam penyajiannya, musik Ndoto dimainkan setelah ubi dimasukan ke dalam rumah adat (setelah ubi dipersembahkan kepada para leluhur). Setelah menyimpan ubi, alat musik Ndoto dikeluarkan dari rumah adat, kemudian akan dimainkan oleh para pemain. Posisi pemain yakni membelakangi rumah adat dan menghadap ke Peo (simbol persatuan dan persaudaraan masyarakat Nagekeo).

Ragam-ragam yang dimainkan dalam musik Ndoto merupakan cerminan dari kehidupan masyarakat Wajo, yang kemudian diaplikasikan ke dalam musik. Tempo cepat pada ragam gore ine oe, ma'e taku goe (jangan takut dengan segala beban, melainkan harus bisa dijalani) melambangkan semangat masyarakat Wajo dalam menjalani kehidupan, dan gaya bersahut-sahutan pada ragam ndua reta uma nuka wodo ko'u, bhida kodo ta tekuku tekuku (dalam menyelesaikan suatu pekerjaan walaupun berat, tetap harus dijalani agar memperoleh hasil yang memuaskan meski lelah) melambangkan ada masyarakat yang mengalami kesulitan, namun tidak perlu khawatir karena masyarakat yang lain ada untuk membantu.

Alat musik Ndoto juga berfungsi sebagai kayu bakar guna merebus ubi. Hal tersebut merupakan bagian dari habitus tokoh adat, dilakukan guna mengantisipasi adanya permainan musik Ndoto di kampung adat setelah ritual selesai dilaksanakan. Jika dikaitkan dengan kehidupan masyarakat Wajo, maka dapat diinterpretasikan pembuatan alat musik Ndoto, permainan alat musik Ndoto, dan penggunaannya sebagai kayu bakar adalah modal budaya dari kehidupan masyarakat Wajo, yakni mereka dilahirkan (pembuatan alat musik Ndoto), menjalani kehidupan (permainan alat musik Ndoto), dan sampai pada kematian atau kembali kepada sang pencipta (penggunaan alat musik Ndoto sebagai kayu bakar).

Dalam pelaksanaannya, Uwi (ubi jalar liar) dijadikan persembahan kepada 
para leluhur. Ritual Ngagha Mere tidak terlepas dari musik, yakni musik Ndoto (bambu). Musik tersebut sangat penting peranannya dalam ritual Ngagha Mere, karena merupakan sarana komunikasi masyarakat Wajo kepada para leluhur. Masyarakat Wajo percaya bahwa ketika musik tersebut dimainkan, para leluhur akan mendengar, dan mengetahui bahwa anak cucunya datang untuk memberikan persembahan. Musik Ndoto memiliki beberapa ragam dan ragam-ragam tersebut berkaitan erat dengan kehidupan masyarakat Wajo. Motif-motif yang dimainkan dalam ragam mencerminkan kehidupan masyarakat Wajo yang selalu menanamkan semangat dalam menjalani hidup, serta gotong-royong dalam kehidupan masyarakatnya. Alat musik Ndoto tidak hanya digunakan sebagai sarana komusikasi, tetapi juga dijadikan sebagai kayu bakar guna merebus uwi (ubi jalar liar). Hal tersebut dilakukan guna mengantisipasi adanya permainan musik Ndoto di kampung adat, sebab alat musik itu tidak boleh lagi dimainkan di kampung adat setelah ubi dipersembahkan kepada para leluhur. Namun jika dihubungkan ke dalam kehidupan masyarakat Wajo, dapat diinterpretasikan bahwa pembuatan alat musik Ndoto melambangkan sebagai kelahiran manusia, permainan musik Ndoto sebagai proses menjani hidup, dan penggunaannya sebagai kayu bakar melambangkan kematian atau berpulangnya manusia kepada sang pencipta.

\section{Daftar Pustaka}

Arikunto, Suharsimi. 2013. Prosedur Penelitian Suatu Pendekatan Praktik. Jakarta: Rineka Cipta.

Bai, Edelburga Glidius. 2016. "Daftar Isian Potensi Desa dan Kelurahan, Lampiran II: Peraturan Menteri Dalam Negeri Nomor 12 Thun 2007 Tanggal 10 Maret 2007'. Tidak Terbit.

Creswell, John. 2012. Research design kualitatif, kuantitatif, mixed. Terjemahan. Yogyakarta: Pustaka Pelajar.

Djohan. 2009. Psikologi Musik. Yogyakarta: Best Publisher Cet. III.

Hendarto, Sri. 2011. Organologi dan Akustika I \& II. Bandung: CV Lubuk Agung.

Langer, Suzanne K. 2006. Problematika Seni. Bandung: STSI Bandung.

Nakagawa, Shin. 2000. Musik dan Kosmos Sebuah Pengantar Etnomusikologi. Jakarta: Yayasan Obor Indonesia 
Soedarsono, R.M. 2002. Seni Pertunjukan Indonesia di Era Globalisasi. Yogyakarta: Gadjah Mada University Press.

Statistics of Nagekeo Regency, Badan Pusat Statistik Kabupeten Nagekeo. 2016. Kabupaten Nagekeo dalam Angka, Nagekeo Regency in Figures. Nagekeo: BPS Kabupaten Nagakeo/Statistics Nagakeo

Stenly. 2008. "Wajo dalam Sejarah. Tidak Terbit. 